\title{
Glycation of rat sciatic nerve tubulin in experimental diabetes mellitus
}

\author{
N. A. Cullum, J. Mahon, K.Stringer and W. G. McLean \\ Department of Pharmacology and Therapeutics, University of Liverpool, Liverpool, UK
}

\begin{abstract}
Summary. Diabetic neuropathy is associated with some early defects of axonal transport in experimental animals. Axonal transport is dependent on intact microtubules, and unsubstituted lysine residues of tubulin are essential for microtubule polymerization. As lysine residues are the major target for the non-enzymatic attachment of glucose, the effect of diabetes on the extent of glycation of tubulin was investigated. There was a more than four-fold increase in the extent of glycation of tubulin in the sciatic nerve of rats with streptozotocin-induced diabetes of 2 weeks duration compared with control rats. In contrast, no such increase in glycation was ob-
\end{abstract}

served in brain microtubule protein from diabetic rats at that stage of diabetes. Incubation of brain microtubule protein with glucose prior to in vitro polymerization showed that the early stages of glycation were not associated with inhibition of microtubule assembly. The observed glycation of peripheral nerve tubulin in early experimental diabetes may nevertheless contribute to axonal transport abnormalities through an as yet undetermined impairment of microtubule function.

Key words: Diabetes, glycation, tubulin, microtubule, sciatic nerve, brain, axonal transport.
Non-enzymatic glycation of peripheral nerve protein is increased in experimental diabetes [1]; however the precise nerve proteins undergoing glycation have not been characterised.

Certain aspects of axonal transport are compromised at an early stage in the diabetic rat [2,3]. Fast anterograde and retrograde axonal transport are dependent on intact microtubules [4], while slow axonal transport involves movement of axonal microtubules or their subunit proteins [5]. Williams et al. [6] described a significant increase in the extent of glycation of rat brain microtubule protein, and an associated decrease in in vitro polymerization of microtubule protein after streptozotocin-diabetes of unspecified duration. We sought to determine if such an increased glycation was found in peripheral nerve as early as 14 days after streptozotocin-induced diabetes, a time when the first axonal transport abnormalities are known to occur.

\section{Materials and methods \\ Induction of diabetes}

Diabetes was induced in female Wistar rats (weight 200-250 g) by a single intraperitoneal injection of $60 \mathrm{mg} / \mathrm{kg}$ streptozotocin. Rats with a non-fasting blood glucose $>15 \mathrm{mmol} / \mathrm{l}$ were considered to be diabetic.

\section{Preparation of tubulin from rat sciatic nerve and brain and measurement of glycation}

Fourteen days after injection of streptozotocin, diabetic and agematched control rats were killed and one sciatic nerve (30-50 $\mathrm{mg}$ wet weight) from each animal was homogenized in $1 \mathrm{ml}$ of ice-cold $0.1 \mathrm{mmol} / 1$ sodium phosphate buffer, $\mathrm{pH}$ 7.0. Brain microtubule proteins were also prepared up to a first cycle of polymerization, as for pig brain (see below). The homogenates were then incubated with $1 \mathrm{mg}$ sodium borohydride $\left(\mathrm{NaB}^{3} \mathrm{H}_{4}\right)$, specific activity $5-20 \mathrm{Ci} / \mathrm{mmol}$ (Amersham International plc, Amersham, Bucks., UK) for 40 min at room temperature. The reduced homogenates were dialysed to remove unbound radioactivity and the proteins separated by twodimensional polyacrylamide gel electrophoresis by the method of O'Farrell [7], first on isoelectric focussing rod gels pI gradient 5-7 then on $1.5 \mathrm{~mm}$ thick, $6-14 \%$ gradient polyacrylamide slab gels. Proteins were visualised by silver staining. Spots corresponding to $\alpha$ and $\beta$-tubulin [8] were cut from the gel and the gel pieces heated at $55^{\circ} \mathrm{C}$ in $0.5 \mathrm{ml} 30 \%$ hydrogen peroxide overnight to elute the proteins. Samples $(0.5 \mathrm{ml})$ were incubated in $0.5 \mathrm{ml} 6 \mathrm{~mol} / \mathrm{L} \mathrm{HCl}$ in sealed, evacuated tubes at $110^{\circ} \mathrm{C}$ for $12 \mathrm{~h}$. The resulting amino acids were dissolved in $0.5 \mathrm{ml} 25 \mathrm{mmol} / \mathrm{l}$ sodium phosphate buffer, $\mathrm{pH} 9.0$. Aliquots were counted to determine total radioactivity and the remainder was applied to a $1 \mathrm{ml}$ column of Affi-gel 601 (Bio Rad, Hemel Hempstead, Herts., UK). A first fraction, containing nonspecific amino acid-bound radioactivity, was eluted with $50 \mathrm{ml}$ of $25 \mathrm{mmol} / \mathrm{l}$ phosphate buffer $\mathrm{pH}$ 9.0. The second fraction, containing the radiolabelled, borohydride-reduced glycated amino acids, was eluted with $50 \mathrm{ml} 25 \mathrm{mmol} / \mathrm{l} \mathrm{HCl}$. Aliquots of each fraction were analysed by liquid scintillation counting. 


\section{Purification of pig brain microtubule protein and in vitro polymerization}

Pig brains were homogenised in a buffer consisting of $100 \mathrm{mmol} / 1$ piperazine-N, N'-bis(2-ethane) sulphonic acid (PIPES); $1 \mathrm{mmol} / 1$ $\mathrm{MgCl}_{2} ; 1 \mathrm{mmol} / \mathrm{l}$ ethylene glycol-bis(-aminoethylyether) $\mathrm{N}, \mathrm{N}, \mathrm{N}^{1}$, $\mathrm{N}^{1}$-tetraacetic acid (EGTA), pH 6.8 (buffer A) at $4^{\circ} \mathrm{C}$. The resulting homogenate was centrifuged at $75,000 \mathrm{~g}$ for $1 \mathrm{~h}$ at $4^{\circ} \mathrm{C}$. The supernatant obtained was incubated with a half-volume of $100 \%$ glycerol and $0.5 \mathrm{mmol} / \mathrm{l} \mathrm{GTP}$ for $20 \mathrm{~min}$ at $37^{\circ} \mathrm{C}$ to permit a first cycle of microtubule polymerization, and then centrifuged at $85,000 \mathrm{~g}$ for $1.5 \mathrm{~h}$ at $37^{\circ} \mathrm{C}$. The resulting pellet of microtubule protein was resuspended, incubated on ice for $30 \mathrm{~min}$ and then centrifuged at $100,000 \mathrm{~g}$ for $30 \mathrm{~min}$ at $4^{\circ} \mathrm{C}$. GTP was added to $0.5 \mathrm{ml}$ samples of the ensuing supernatant, to a final concentration of $1 \mathrm{mmol} / \mathrm{l}$, and the polymerization into microtubules was measured at $37^{\circ} \mathrm{C}$ as an increase in optical density of the solution at $350 \mathrm{~nm}$ in a Cecil CE599 automatic spectrophotometer. The change in optical density was followed during up to three further cycles of temperature-dependent polymerization, in the presence or absence of $20 \mathrm{mmol} / \mathrm{l}$ glucose, either added directly or $1 \mathrm{~h}$ previously and maintained at $37^{\circ} \mathrm{C}$.

\section{Statistical analysis}

Differences in glycation of tubulin between control and diabetic rats were analysed statistically by the Mann-Whitney U-Test. Differences in extent of assembly were analysed by Student's $t$-test for unpaired data.

\section{Results}

\section{Extent of glycation of sciatic nerve and rat brain tubulin in control and 14-day diabetic rats}

Mean blood glucose after 14 days of diabetes was $19.0 \pm 6.2 \mathrm{mmol} / \mathrm{l}$ compared to that of the control rats at $6.0 \pm 0.6 \mathrm{mmol} / 1$ (mean $\pm \mathrm{SD}, n=5$ in each group).

The extent of glycation of tubulin was expressed as disintegrations per minute (dpm) in the glycated fraction as a $\%$ of the total radioactivity, and is shown in Figure 1. There was a significant increase in the extent of glycation of tubulin in the sciatic nerve of rats after 14 days of streptozotocin-diabetes $(p<0.005)$

The glycation of the once-cycled preparation of rat brain microtubule proteins was expressed as dpm in the glycated fraction per $\mu \mathrm{g}$ protein, since there was adequate protein for it to be assayed in this case. Glycation of microtubule proteins from control rats was $50 \pm 15$ and from diabetic rats was $42 \pm 8 \mathrm{dpm} / \mu \mathrm{g}$ protein (mean $\pm \mathrm{SD}$, $n=5)$.

\section{The effect of preincubation with glucose on the in vitro assembly of pig brain microtubule protein}

Three samples were analysed concurrently each time for the effects of glucose on microtubule assembly. The results are shown in Figure 2. There was no significant effect on porcine microtubule assembly of preincubation with $20 \mathrm{mmol} / \mathrm{l}$ glucose. Identical data were found with a rat microtubule preparation (results not shown).

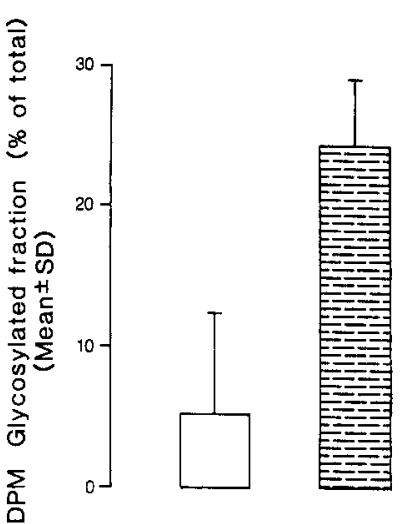

Fig. 1. Tubulin was purified from control $\square$ and streptozotocindiabetic $⿴$ rat sciatic nerve by two-dimensional polyacrylamide gel electrophoresis, reduced with $\mathrm{NaB}^{3} \mathrm{H}_{4}$ and the glycated and non-glycated amino acids separated by phenylboronic acid chromatography. Glycation is expressed as disintegrations per minute (dpm) eluted in the fraction that contains glycated amino acids as a \% of the total bound radioactivity. Results are means $\pm \mathrm{SD}, n=5$ in each group. There is a significant increase in glycation of tubulin after 2 weeks of streptozotocin-diabetes $(p<0.005)$

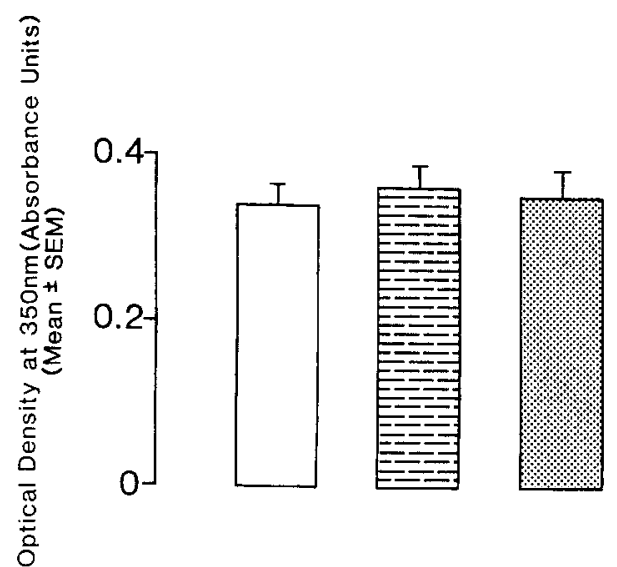

Fig.2. Microtubule protein was purified from pig brain and incubated for $1 \mathrm{~h}$ in the absence or presence of glucose. Polymerization was measured spectophotometrically. Three samples were run concurrently in each experiment; microtubule protein alone $\square$, microtubule protein with glucose added to a final concentration of $20 \mathrm{mmol} / \mathrm{l}$ 目 and microtubule protein incubated with $20 \mathrm{mmol} / \mathrm{lglu}-$ cose for 1 hour $\%$. Results are expressed as mean optical density change \pm SEM for eight experiments using two different microtubule preparations

\section{Discussion}

Previous work by Vlassara and co-workers [1] established an almost three-fold increase in the extent of glycation of peripheral nerve protein of rats with diabetes of 3 months duration; the methods used were the same as those used in this work. Amino acid analysis has pin-pointed the major site of glycation to be lysine residues $[1,9]$. We found the proportion of sciatic nerve tubulin glycated in diabetic rats to be nearly five times that in control rats, although the particular amino acid residues involved were not identified.

Microtubules are essential for axonal transport, a process known to be affected by as early as 14 days of ex- 
perimental diabetes [2,3]. Highly reactive lysine residues are essential for assembly of tubulin into microtubules, and their substitution prevents assembly $[10,11]$. We have now provided direct evidence of an increase in the extent of glycation of peripheral nerve tubulin after 2 weeks of experimental diabetes, at a time when axonal transport abnormalities are known to occur. We were unable, however, to detect any increased glycation of rat brain microtubule proteins at that stage of diabetes. This is in contrast to the work of Williams et al. [6], who showed an increased glycation of rat brain microtubule proteins and implied that even the early stages of glycation impair microtubule assembly. The difference from our results may be that, at 14 days of diabetes, peripheral nerve tubulin is glycated while brain microtubule proteins are not. However, the method those authors used for measuring glycation i.e. by incubation with $\mathrm{NaB}^{3} \mathrm{H}_{4}$ followed merely by dialysis and scintillation counting measures not only reduced ketoamine bonds but also fatty acid esters and peptide bonds. Because the bulk of the radioactivity is thus non-specific, it is necessary to separate the glycated amino acids by phenylboronic acid chromatography [1].

Equally, we have found no evidence that the early stages of glycation of brain microtubule proteins in vitro produced by incubation of proteins with up to $20 \mathrm{mmol} / \mathrm{l}$ glucose, affect the assembly into microtubules. The method used for the measurement of microtubule assembly in this case was the same spectrophotometric one described by Williams et al. [6]. Their preparations, however, displayed kinetic properties which have not been observed in this laboratory, nor described previously in the literature, namely a lag time before polymerization commenced of approximately $12 \mathrm{~min}$. Longer incubation periods with glucose, to effect a greater degree of glycation, were not possible due to the inherent instability of tubulin whilst in solution. Thus, although we showed, as did Williams et al. [6], that some glucose had been incorporated into the porcine microtubule protein preparation after incubation for $1 \mathrm{~h}$ (own unpublished data), we were unable to demonstrate that this early Schiff base formation interferes with the in vitro polymerization of tubulin into microtubules.

The extent to which an increased glycation of peripheral nerve tubulin would interfere with axonal transport remains to be determined. Recent work by Abbate et al. [12] suggests that fast anterograde transport is unaffected and retrograde transport only slightly affected in the sciatic nerve of diabetic rats. The in vitro conditions of their study might permit a reversal of short-term influences on transport that would exist in vivo, but not, presumably, a reversal of non-enzymatic glycation. Tubulin glycation may, however, contribute to the rather more clearly defined changes in slow transport of cytoskeletal proteins in experimental diabetes $[3,13]$ that may be related to reduced axon diameter.

Acknowledgements. This work was supported by the British Diabetic Association and the Mersey Regional Health Authority. We thank Mr. D. Trafford for expert technical help.

\section{References}

1. Vlassara H, Brownlee M, Cerami A (1981) Nonenzymatic glycosylation of peripheral nerve protein in diabetes mellitus. Proc Natl Acad Sci USA 78: 5190-5192

2. Sidenius P, Jakobsen J (1979) Axonal transport in early experimental diabetes. Brain Res 173: 315-330

3. McLean WG, Frizell M, Sjöstrand J (1985) Pathology of axonal transport. In: Lajtha A (ed) Handbook of neurochemistry, Vol. 9. Plenum, New York, pp 67-86

4. Schnapp BJ, Vale RD, Sheetz MP, Reese TS (1985) Single microtubules from squid axoplasm support bidirectional movement of organelles. Cell 40: 455-462

5. Hoffmann PN, Lasek R (1975) The slow component of axonal transport. Identification of major structural polypeptides of the axon and their generality among mammalian neurons. J Cell Biol 66: 351-366

6. Williams SK, Howarth NL, Devenny JJ, Bitensky MW (1982) Structural and functional consequences of increased tubulin glycosylation in diabetes mellitus. Proc Natl Acad Sci USA 79: 6546-6550

7. O'Farrell PH (1975) High resolution two-dimensional electrophoresis of proteins. J Biol Chem 250: 4007-4021

8. McLean WG (1985) Axonal transport of actin and regeneration rate in non-myelinated sensory nerve fibres. Brain Res 333:225260

9. Friedman M (1982) Chemically reactive and unreactive lysine as an index of browning. Diabetes 31 [Suppl. 3]: 5-14

10. Mellado W, Slebe JC, Maccioni RB (1982) Tubulin carbamoylation. Functional amino groups in microtubule assembly. Biochem J 203: 675-681

11. Szasz J, Burn R, Sternlicht H (1982) Effect of reductive methylation on microtubule assembly. J Biol Chem 257: 3697-3704

12. Abbate SL, Atkinson MB, Breuer AC (1991) Amount and speed of fast axonal transport in diabetes. Diabetes 40: 111-117

13. Medori R, Autilio-Gambetti L, Monaco S, Gambetti P (1985) Experimental diabetic neuropathy: impairment of slow axonal transport with changes in axon cross-sectional area. Proc Natl Acad Sci USA 82: 7716-7720

Received: 26 November 1990

and in revised form: 26 February 1991

Dr. W.G. McLean

Department of Pharmacology and Therapeutics

University of Liverpool

PO Box 147

Liverpool L69 3BX

UK 